\title{
DESENHOS DE MOdA de FILIPE FAísCA [ENTREVISTA]
}

Filomena Silvano ${ }^{1}$

NOVA-FCSH, Lisboa, Portugal

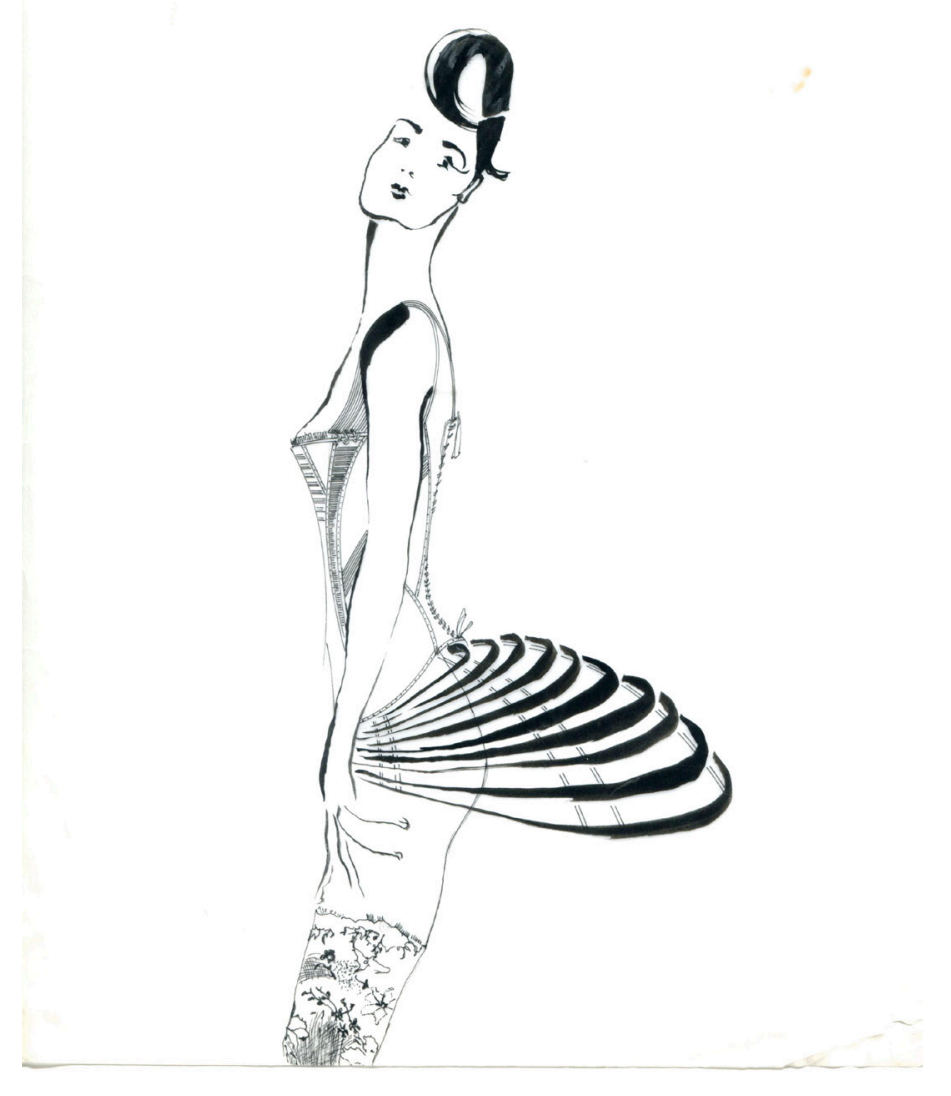

Veja a galeria de desenhos aqui:

https://journals.openedition.org/cadernosaa/2110

$1 \quad$ Faculdade de Ciências Sociais e Humanas, Universidade Nova de Lisboa e Centro em Rede de Investigação em Antropologia (CRIA-FCSH). Contato: fsilvano@fcsh.unl.pt. 
Quando pensamos em Moda, visualizamos sobretudo imagens fotográficas, mas, se nos detivermos um pouco sobre o assunto, conseguimos visualizar também desenhos. Estes são mais raros e podem ser de géneros muito diferentes. A multiplicidade resulta do facto de o uso do desenho surgir, com propósitos distintos, em momentos sucessivos do processo criativo.

O desenho de esquiço serve para procurar soluções de design e surge no início, quando a matéria ainda se encontra numa espécie de suspensão. Fazê-lo, é quase sempre um trabalho solitário. Cada desenhador convoca, através da mão e do traço, o seu próprio arquivo de formas e de ideias. Uma vez apontadas as soluções, o desenho serve para as comunicar, antes de mais, aos profissionais das equipas dos ateliers, mas também aos clientes. Estabelece uma relação com o que será a peça de roupa, permite que nos projetemos nela, mas não poderá nunca autonomizar-se, sob pena de a ligação entre o desenho e o objeto se perder. Os vários tipos de desenho técnico dão indicações relativas à execução. No fim, o desenho de ilustração integra as roupas em universos ficcionais que lhes dão uma existência muitas vezes paralela às suas vidas materiais, passadas a vestir os corpos de pessoas reais.

Cada criador usa o desenho à sua maneira e esse uso determina a dinâmica de trabalho de cada atelier. Filipe Faísca é um designer português cujo trabalho se desenvolve num pequeno atelier que executa a quase totalidade das peças mostradas em desfile duas vezes por ano - na Moda Lisboa - bem como as encomendas de peças únicas. Depois de um semestre de acompanhamento etnográfico do seu trabalho, fiz-lhe uma entrevista sobre as formas como usa o desenho, aqui apresentada em conjunto com uma seleção de desenhos.

Filipe Faísca: Uso o desenho para me focar. Não é uma disciplina obrigatória porque tenho uma relação com a matéria muito forte. Uso o desenho quando tenho de me relacionar com o corpo.

Filomena Silvano: De quem?

Com o corpo, ponto final. Normalmente a peça pode estar toda desenhada na minha cabeça, mas preciso de a relacionar com o corpo. Então aí necessito muito do desenho. Preciso de a passar para o papel, de a relacionar com o corpo.

O desenho serve para encontrar respostas para problemas de construção das peças de roupa, ou é só uma transcrição do que está na cabeça?

Uma transcrição do que está na cabeça.

Há designers que afirmam que o desenho vai buscar coisas que de outro modo não se revelariam. Surgem no traçar.

Isso não me acontece, de todo. De todo.

Tu visualizas (se assim se pode dizer) a peça na cabeça e depois transcreve-la para o papel.

Sim. A minha relação com o desenho é diferente. 
Não funciona como um esquiço, como um dispositivo de procura?

Não. Eu não descubro nada com o desenho. A única coisa que eu encontro é o que o meu corpo sente através da mão. $O$ que é que o meu corpo me diz sobre aquilo que eu estou a ver. Há um entusiasmo com aquilo que eu estou a ver e esse entusiasmo é representado pela mão. Isso acontece também nos croquis de moda, onde trabalho a partir da peça já executada. Há sempre um entusiasmo enquanto eu estou a desenhar um fato e isso passa para o papel. Devido à relação muito forte que tenho com a matéria, passo por cima dessa disciplina que é o desenho de esquiço; mas eu adoro desenhar, adoro desenho à vista. O desenho é uma disciplina em que é preciso treinar-se muito. Quanto mais relação se tem com o desenho, mais coisas se descobrem. É verdade. E daí essa tal coisa que tu dizes, de descobrir coisas através do desenho. Isso acho que é possível. Não acontece comigo, devido à pouca relação que eu tenho com o desenho, mas acredito verdadeiramente que isso possa acontecer. Lembro-me que quando estudei desenho durante um ano - e desenhei muito nesse período - eu fui alertado, sensibilizado para o desenho, e de facto eu via muito mais do que habitualmente vejo.

\section{No real?}

Sim, via. Vê-se muito mais. Quando se para para desenhar, vê-se de facto muito mais. Porque os exercícios a isso obrigam. Pede-se para vermos coisas que nós habitualmente não paramos para ver.

Os antropólogos que usam o desenho dizem isso: desenhando, veem as coisas de outra maneira.

Não as vias, se não fosse assim. Tu treinaste o teu olho de determinada maneira e vês as coisas dessa maneira. Se não te treinares para estares em constante mutação, para te permitires mudar o teu olhar e a tua visão, não tens forma de sair de lá.

Não é esse o desenho que fazes...

Não. Desenhar é uma coisa diária. Eu tenho estado a fazer mudanças em casa e estive a ver os desenhos que fiz. A olhar as características do meu desenho. E deu-me saudades de desenhar, de facto. De criar espaço e tempo para voltar a desenhar. Mas certamente não serão desenhos de moda.

Mas tens bastantes desenhos de moda e eles são desenhos muito diferentes (desenho1). Nestes, que são uma série de sobreposiçôes, fico com a sensação de que estás à procura de uma forma para o vestido (desenhos 2, 3, 4 e 5).

Neste, absolutamente.

Depois há alguns que têm uma função de comunicação. De comunicar com a cliente (e se calhar também com as costureiras). Este, eu gosto muito, com o tecido estampado com os desenhos feitos pelas meninas doentes com quem trabalbaste.

Neste eu já tinha o tecido e queria ver como funcionava o padrão numa saia e num casaco. Precisei do desenho para isso. 
Foi uma tentativa de representar o que vai ser o real, para ver se funciona. E este, com o mesmo tecido mas com a saia rodada em chapéu de sol (desenho 6)?

A Moda Lisboa pediu-me croquis para apresentar a coleção. O vestido já estava feito e eu fiz um croquis a representar o vestido.

Então o vestido foi feito a partir da matéria.

$\mathrm{O}$ vestido foi feito sem desenho, sim. $\mathrm{O}$ croquis foi feito à vista.

Mas também tens desenhos realizados antes das peças.

Sim. Estes, feitos a lápis, eu gosto imenso (desenhos 7, 8, 9 e 10). Porquê? porque estes são mesmo estudos. Esta coleção eu desenhei-a antes de a fazer. E os desenhos depois foram executados.

Aqui já tens de responder a uma coisa muito precisa. O corpo da cliente. Desenhas a silhueta da cliente (desenho 11). É porque tens de respeitar o corpo dela?

É. E foi uma coisa feita de raiz. Ela não trouxe nada. Tecidos ou ideias. Eu apresentei-lhe esse desenho.

Há designers que falam na existência de uma liberdade, quando usam o desenho, que resulta de uma espécie de suspensão da matéria. É como se a matéria ficasse ali de lado e os constrangimentos a que ela obriga deixassem de existir durante esse tempo. No teu caso, isso não te diz nada?

Não.

Então quando tu desenhas em que medida é que a matéria está lá?

Olha ali (desenho 12).

Sente-se o plissado do tecido?

Sim. O casaco já estava feito e o desenho não descobriu nada.

Porque fizeste o desenho?

Porque eu adoro fazer isso. Quando estou a adorar o que estou a fazer, adoro o resultado do desenho da peça.

Mas vem depois, só pelo prazer do desenho, ou é como se percebesses melhor a peça desenhando-a? Haverá uma razão...

Pelo prazer do desenho. E há também a importância de deixares o registo daquela peça. É como selar a peça. Torna-a muito mais valiosa, porque tenho o desenho dela.

Dá-lhe uma outra existência, no fim.

Dá, dá. Tens o trabalho do António Lopez, que nas décadas de 1970 e de 1980 trabalhou para todos os designers. Ele ilustrava. É um trabalho que se faz no final e que deixa um registo. Ele ilustrava e aqueles vestidos lindos ficavam marcados pela griffe do António. Tinham sido 
desenhados pelo António. É acrescentar mais qualquer coisa a todo o processo. Há a coleção a que o vestido pertenceu, quem o vestiu e quem o desenhou.

Uma parte dos teus desenhos tem a ver com isso.

Sim. Este, por exemplo, foi para ser publicado no jornal O Público. Fez primeira página.

E para fazer os bordados em colaboração com as bordadeiras da Madeira, também foi preciso desenhar?

Esse é o desenho de pormenor (desenho 13). Todas as decorações precisam dele. Tudo é desenhado milimetricamente. Quando estamos a usar elementos florais ou animais e temos de os bordar.

\section{Falas das borboletas e das abelhas?}

Sim. Essa modificação do mundo animal para o bordado, eu tento reproduzi-la, através dos traços, pensando na maneira como artesanalmente se vai fazer, a forma a que se vai chegar. Do mundo animal há representações com variados filtros. Eu escolhi representações científicas para mostrar como eu queria os animais representados; mas sabia que não era possível bordar com a finura, com a espessura com que as asas de uma borboleta são feitas na realidade. Portanto pedi às estagiárias que estavam a trabalhar comigo que fossem ao ínfimo pormenor e depois fizessem a transformação. Foi feito primeiro à mão e depois foi passado para o computador. 